\title{
Prognostic factors of overall survival for patients with stage II colon cancer
}

\author{
Harsha Trivedi, Ushasree Chamarthy, Luciano Dicarlo, James Herman, Gordan Srkalovic
}

Sparrow Cancer Center, Sparrow Health System, Lansing, Michigan, USA

Corresponding author:
Gordan Srkalovic
College of Human Medicine
Michigan State University, East Lansing, MI
Gordan.Srkalovic@sparrow.org
Tel.: + 5173642809
Fax: + 5173643687

Received: 5 May 2014

Accepted: 17 November 2014

Copyright (C) 2014 by

Academy of Sciences and Arts of Bosnia and Herzegovina.

E-mail for permission to publish: amabih@anubih.ba

\begin{abstract}
Objective. To analyze factors influencing survival of patients with stage II colon cancer treated at our cancer center (Sparrow Hospital) from February 1996 through December 2006. Patients and methods. Survival analyses on 197 patients' age $71.1 \pm 0.9$ years (29 to 97 ) were done using SAS system (V9.3, Cary NC). Analysis included age, gender, stage, surgery type, number of examined lymph nodes, pathological grade, tumor size and the use of adjuvant chemotherapy. Results. Mean follow up length was $48.1 \pm 2.3$ months (0.1-133) and $56 \pm 3.3(0.2-133)$ for survivors. The average number of removed lymph nodes was $18 \pm 13$ (1-103). Adjuvant chemotherapy treatment (5-FU \pm leucovorin) was given to 49 patients, while others (148) were followed expectantly. There were 90 deaths during follow up. Only age exhibits a statistically significant relationship to survival (Hazard Ratio (HR) $=1.06,95 \% \mathrm{CI}=1.03-1.08, \mathrm{p}<0.001$ ). Adjuvant chemotherapy possibly reduced the risk of death by $42 \%$ approaching a borderline advantage for survival $(\mathrm{HR}=0.58, \mathrm{CI}=0.33-1.03, \mathrm{p}=0.06$. The number of removed lymph nodes also showed a possible relationship to survival $(\mathrm{HR}=0.98, \mathrm{CI}=0.62-1.56, \mathrm{p}=0.07)$. Other investigated factors (gender, type of surgery, etc.) were not significant correlates. Conclusion. In this study we found that the most important factor for survival of patients with Stage II colon cancer is the patient's age. Adjuvant chemotherapy showed a borderline significance while the number of resected lymph nodes seemed to be an important survival factor. However, in our study statistical significance was not achieved.
\end{abstract}

Key words: Stage II colon cancer, Chemotherapy, Survival rates, Prognostic factor.

\section{Introduction}

For more than 20 years, adjuvant chemotherapy has been shown to improve diseasefree survival (DFS) and overall survival (OS) in advanced colon cancer. Although it is agreed that patients with stage III disease benefit from adjuvant treatment, whether all patients with stage II disease should receive such treatment remains controversial.
At the center of this controversy are the contradictory conclusions derived by two large investigators' groups. The National Surgical Adjuvant Breast and Bowel Project (NSABP) concluded that the relative benefits of treatment were largely the same for stage II and stage III tumors (1), whereas the International Multicenter Pooled Analysis of B2 Colon Cancer Trials (IMPACT B2) failed 
to demonstrate a statistically significant benefit for stage II tumors $(2,3)$.

FOLFOX has been approved in the adjuvant setting for stage III disease however the value of adjuvant therapy for stage II disease has been debated for decades. Recent data from large trials as well as pooled analyses seem to support its use (4-11). FU-based adjuvant chemotherapy in stage II patients is associated with a $2 \%$ to $4 \%$ benefit in 5 -year DFS compared with surgery alone. On the basis of the MOSAIC results, adjuvant therapy for stage II patients with FOLFOX provides an improvement of $2.7 \%$ in 3-year DFS and 3.8\% in 4-year DFS compared with optimized (infusional) FU/LV therapy $(6,7)$. If we postulate a $6 \%$ gain in 3-year DFS with FOLFOX in unselected stage II patients, this would translate an additional 1,250 patients free of disease every year in the United States (12). In the US Surveillance, Epidemiology and End Results (SEER) Medicare population based study it was noted that treatment is being administered to a significant proportion of patients with low risk stage II colon cancer (13).

For stage II colon cancer, several wellknown pathological and clinical factors are reported for instance: the age of the patient at diagnosis, tumor staging, number of involved lymph nodes, lymphovascular invasion, tumor grade and presence of bowel obstruction are associated with a higher risk of recurrence or death from the cancer. Identifying these factors is important to determine which patients may benefit the most from adjuvant therapy.

In the present study we sought to examine retrospectively the data of patients with Stage II colon cancer seen and treated at Sparrow Hospital from February 1996 through December 2006. There were 197 patients. Our aim was to 1) to find out if we can find an association of the reported factors with overall survival and disease free survival in our patients, 2) we sought to do this as our oncologists also face a similar complex decision of treatment versus no treatment for stage II colon cancer patients and 3) finally we wanted to compare the survival of patients at our center to the national statistics for USA based on the factual information from our data outside the context of controlled clinical trials.

\section{Patients and methods}

We reviewed data of 197 patients who were examined, surgically treated and followed up by oncologists at Sparrow Hospital in Michigan for a ten-year time spanning from February 1996 through December 2006. The time to progression (TTP) was not calculated due to too few events observed in the follow up. Included in the analysis were: age, gender, stage (IIA vs. IIB), surgery type, number of examined lymph nodes, histological grade (well vs. moderately vs. poorly differentiated), tumor size and the use of adjuvant chemotherapy.

\section{Statistical analysis}

All data and survival analysis were performed using SAS statistical software (V9.3 (SAS Institute Inc., Cary, N.C.). Disease free survival (DFS) and Overall survival (OS) experience was characterized by constructing Kaplan-Meier survival curves. Cox proportional hazards models were used to assess differences in survival by baseline characteristics. For Disease free survival only cases with a notation of "Disease Free" were considered. This conservative approach was thought appropriate by the statistician as some cases marked as "Unknown" may well have been disease free. Subjects who died but whose deaths were determined to be unrelated to disease were censored at the time of last contact. A Type I error protection rate of 0.05 was assumed. All $P$ values of less than .05 were considered statistically significant. 


\section{Ethics statement}

This project was reviewed and was deemed as "an Exempt from IRB review status" by the Sparrow Institutional Research Review Committee (IRRC) according to the USA federal regulations. The confidentiality and the privacy of the subjects and the data were maintained as the data was obtained as anonymous from the tumor registry. No attempt was made to identify individuals. All authors have completed the Human subject Training required by the Sparrow IRRC and have adhered to ethical standards of Human subject research.

\section{Results}

Analysis was performed on 197 patients with Stage II colon cancer patients age 71.1 \pm 0.9 years (range 29 to 97 ). Of the 197 patients, 114 were female (58\%) and $83(42 \%)$ were male. Subtotal colectomy was performed on
$142(72 \%)$ patients, while partial colectomy and local resection were done on 38 (19.8\%), and $3(1.6 \%)$ patients respectively. Total colectomy was done on 14 patients $(7.1 \%)$. Out of 197 patients, $51(25.8 \%)$ were Stage IIA and $146(74.1 \%)$ stage IIB. Average number of removed lymph nodes was $18 \pm 13$. Most of the cancers $(145,73.6 \%)$ were moderately differentiated, 23 (11.7\%) well differentiated, $22(11.2 \%)$ poorly differentiated, while one patient had undifferentiated cancer. Eight biopsies $(4.1 \%)$ were not classified. Tumor sizes were available for 175 patients with a mean size of $5.2 \pm 0.2 \mathrm{~cm}$ (range $0-16.5$ ). Adjuvant chemotherapy treatment $(5-\mathrm{FU} \pm \mathrm{LV}$ in almost all cases) was given to $47(23.9 \%)$ patients, while the rest (150 patients, $76.1 \%$ ) were followed expectantly.

The mean length of follow up for all patients (197 total) was $48.1 \pm 2.3$ months (0.1-133) and 56 $\pm 3.3(0.2-133)$ for survivors. There were 90 deaths (45.7\%) recorded

Table 1 Results from the Cox regression Univariate analysis for survival

\begin{tabular}{|c|c|c|c|c|}
\hline Variable & Categories & $\mathrm{p}$-value & Hazard ratio & $\mathrm{Cl} 95 \%$ \\
\hline Age (years) & $29-97$ & $<0.001$ & 1.06 & $1.03-1.08$ \\
\hline \multirow{2}{*}{ Gender } & Female $(n=114)$ & \multirow{2}{*}{0.410} & \multirow{2}{*}{0.84} & \multirow{2}{*}{$0.56-1.27$} \\
\hline & Male $(n=83)$ & & & \\
\hline \multirow{4}{*}{ Type of surgery } & Total colectomy $(n=14)$ & \multirow{4}{*}{$\begin{array}{l}0.563 \\
\text { (for any differences } \\
\text { by surgery type) }\end{array}$} & \multirow{4}{*}{ Not done } & \multirow{4}{*}{ Not done } \\
\hline & Hemi colectomy $(n=142)$ & & & \\
\hline & Partial colectomy $(n=38)$ & & & \\
\hline & Local resection ( $n=3$ ) & & & \\
\hline \multirow{2}{*}{ Tumor stage } & Stage $2 A c(n=51)$ & \multirow{2}{*}{0.311} & \multirow{2}{*}{1.34} & \multirow{2}{*}{$0.76-2.35$} \\
\hline & Stage $2 B(n=146)$ & & & \\
\hline \multirow{2}{*}{ Adjuvant chemotherapy } & $5 F U+/-\operatorname{LV}(n=47)$ & \multirow{2}{*}{0.056} & \multirow{2}{*}{0.58} & \multirow{2}{*}{$0.33-1.03$} \\
\hline & Follow-up expectantly $(n=150)$ & & & \\
\hline \multirow{2}{*}{ Number of lymph nodes removed } & $>12$ & \multirow{2}{*}{0.07} & \multirow{2}{*}{0.98} & \multirow{2}{*}{$0.62-1.56$} \\
\hline & $<12$ & & & \\
\hline \multirow{4}{*}{ Histological grade of tumor } & Moderate differentiation $(n=145)$ & \multirow{4}{*}{0.77} & \multirow{4}{*}{0.93} & \multirow{4}{*}{$0.58-1.51$} \\
\hline & Well differentiated $(n=23)$ & & & \\
\hline & Poorly differentiated $(n=22)$ & & & \\
\hline & Undifferentiated $(n=1)$ & & & \\
\hline
\end{tabular}

Hazard ratio (with 95\% confidence interval and p-values) estimates the relative risk of death associated with each variable. 
during the follow up. Only age exhibits a statistically significant relationship to the sur$\operatorname{vival}(\mathrm{HR}=1.06,95 \% \mathrm{CI}=1.03-0.08, \mathrm{p}<0.001)$ (Table 1).

Treatment with adjuvant chemotherapy showed definite trend toward superior survival with risk of mortality from colon cancer been reduced by $42 \% \quad(\mathrm{HR}=0.58$, $95 \% \mathrm{CI}=0.33-1.03)$. However, statistical significance did not reach previously defined level of confidence $(p=0.056)$. Number of removed lymph nodes also showed possible relationship to the survival, although the results were not statistically significant $(\mathrm{HR}=0.98,95 \% \mathrm{CI}=0.33-1.03, \mathrm{p}=0.07)$. Other analyzed factors ; Gender $(\mathrm{HR}=0.84$, $95 \% \mathrm{CI}=0.56-1.27, \mathrm{p}=0.41$, type of surgery $(\mathrm{p}=0.563$ for any difference in all surgery types), stage of the tumor $(\mathrm{HR}=1.34$, 95\% CI $=0.76-2.35, \quad \mathrm{p}=0.311)$, histological grade $(\mathrm{HR}=0.93,95 \% \mathrm{CI}=0.58-1.51$, $\mathrm{p}=0.77)$ and the size of the tumor $(\mathrm{HR}=1.00$,
$95 \% \mathrm{CI}=0.92-1.09, \mathrm{p}=0.93)$ were not significant survival correlates. At 12 months overall PFS was $94 \%, 90 \%$ at 24 months and $78 \%$ at 60 months (Figure 1).

For progression free survival (disease free survival) only cases with a notation of "Disease Free" were considered to be free from progression. This is a conservative approach (but likely appropriate) as some cases marked as "Unknown" may well have been disease free. Subjects who died but whose deaths were determined to be unrelated to disease were censored at that point.

Overall survival (OS) for all patients was $90 \%$ at 12 months, $82 \%$ at 24 months and $56 \%$ at 60 months (Figure 2).

Patients more than 80 years old had 24 and 60 months survival of $66 \%$ and $33 \%$, while at same time points, $92 \%$ and $78 \%$ of patients younger than 63 were still alive (Figure 3)

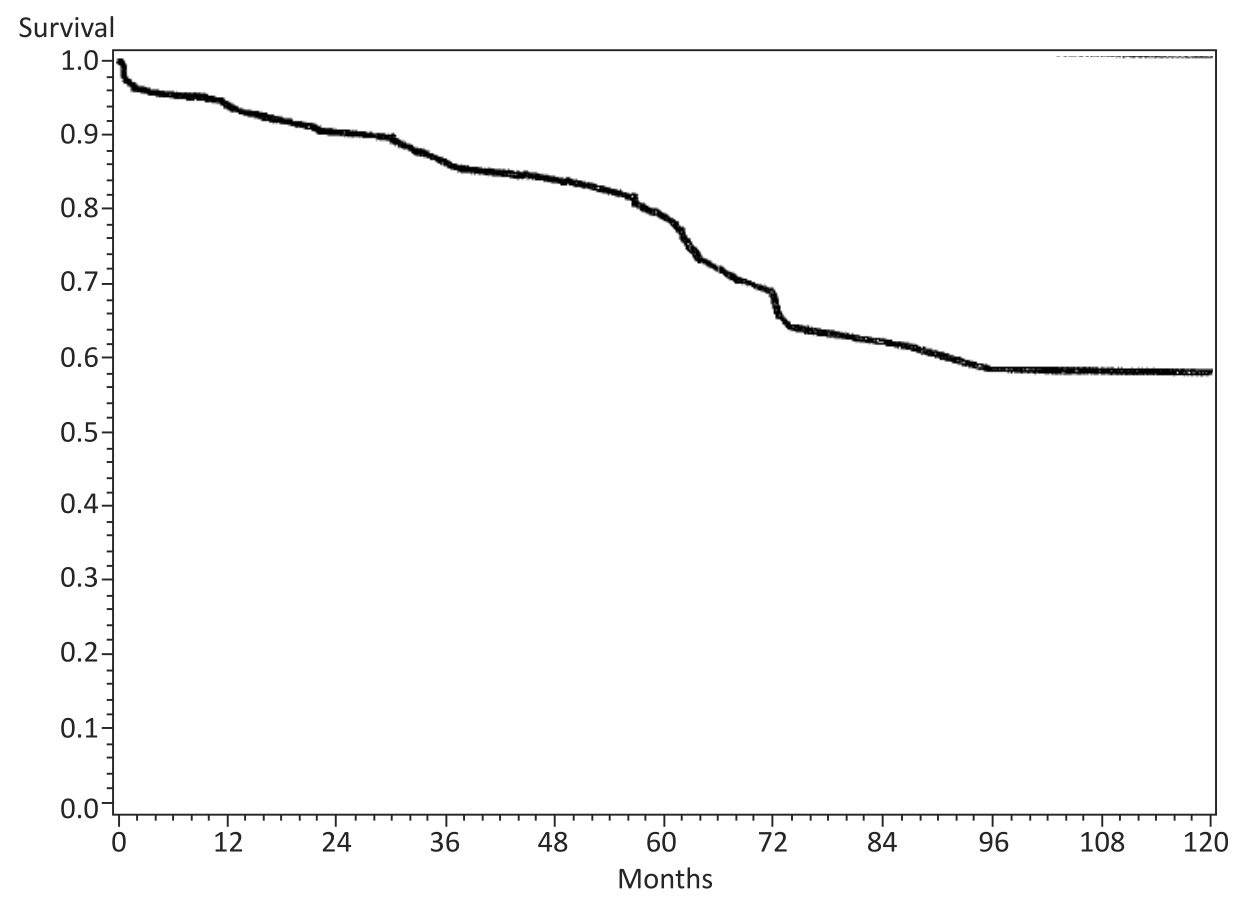

Figure 1 Progression Free Survival. Kaplan-Meier survival curve for 197 patients with Stage II colon cancer treated at Sparrow Hospital from 1996-2006. 


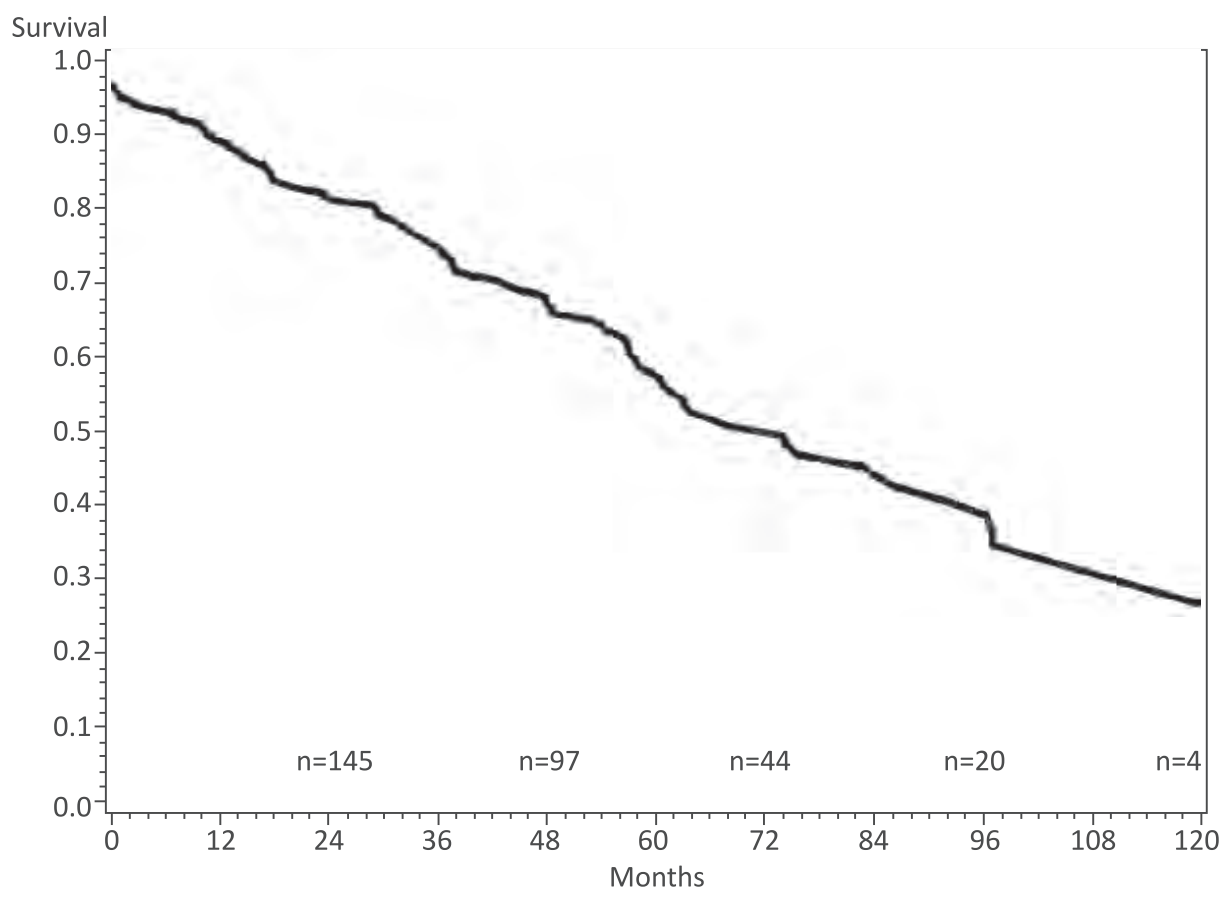

Figure 2 Overall Survival. Kaplan-Meier survival curve for 197 patients with Stage II colon cancer treated at Sparrow Hospital from 1996-2006. Numbers of patients remaining are indicated at 24 month increments.

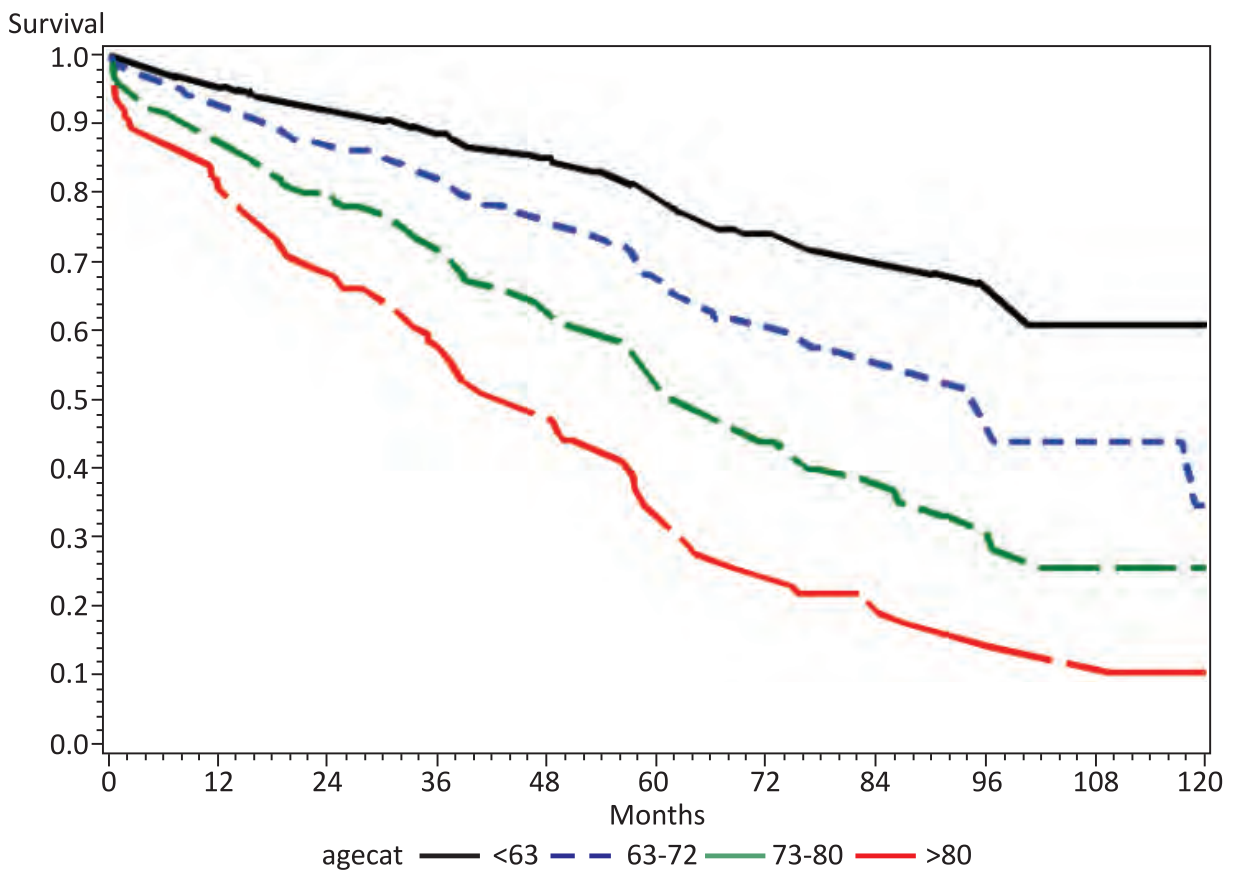

Figure 3 Overall Survival by Age. Kaplan-Meier survival curves for 197 patients with Stage II colon cancer treated at Sparrow Hospital from 1996-2007, stratified by age $(<63,63-72,73-80$ and $>80)$. 


\section{Discussion}

The role of adjuvant chemotherapy in completely resected, pathological stage II colorectal cancer is an important unresolved area in the clinical care of the cancer patient. It warrants further investigation of survival factors in this population. Randomized controlled trials and meta-analyses have uniformly failed to definitively detect a survival benefit for adjuvant chemotherapy in stage II colon cancer. These trials have included insufficient numbers of patients with stage II disease to ultimately determine whether adjuvant chemotherapy in this population is truly beneficial. Nonetheless, there remains no clinical or biological reason to believe that the clinical behavior of stage II tumors should be different from that of stage III tumors. Analysis of pooled data from 4 NSABP studies and IMPACT B report raised more questions than answers about adjuvant chemotherapy in these patients (1-3). In the IMPACT B2 meta-analysis of stage II subgroups from five adjuvant trials, nonsignificant trends for improvements in DFS (73\% vs. $76 \%)$ and OS ( $80 \%$ vs. $82 \%)$ were reported $(4,5)$. A separate pooled-analysis of four consecutive NSABP adjuvant trials demonstrated consistent treatment benefits in both stage II and stage III patients, but interpretation was limited because of the heterogeneity of the treatments and control arms in the included trials (1). A differential magnitude of benefit was observed in a separate analysis done by Gill et al., with proportional reductions in risk of recurrence by $17 \%$ and death by $15 \%$ for nodenegative disease as compared with $40 \%$ and $35 \%$, respectively, for node-positive disease (10). A biologic explanation for a differential effectiveness of adjuvant FU-based therapy between node-negative and node-positive colon cancers has not been elucidated. It may be postulated that this effect is associated with Microsatellite instability (MSI), as a greater proportion of node-negative colon cancers observed have MSI-H phenotype (14). Survival of 23,017 patients with Stage II colon cancer from American College of Surgeon Commission on Cancer (CoC) National Cancer Database (NCD) showed that $87.7 \%$ were alive at 12 months, $80.1 \%$ at 24 months and $61.4 \%$ at 60 months (15). Data from this large database are very similar to the findings in our study with $90 \%, 82 \%$ and $56 \%$ survival at corresponding times. Observed 5-year survival rates for patients with stage II colon cancer from the same database diagnosed in 2000 were superior with adjuvant chemotherapy when compared to those who were observed (55.7\% vs. $36.4 \%)$ (15-16). Although several statistically underpowered studies have not shown significant evidence of prolonged survival with adjuvant chemotherapy for patients with stage II colon cancer, a reduced risk of recurrence was seen retrospectively in the MOSAIC trial of adjuvant FOLFOX therapy for patients with high-risk stage II disease. Stage II colon cancer still presents a significant therapeutic challenge. Indeed, expert panels from both the National Cooperative Cancer Network (NCCN) and the American Society of Clinical Oncology (ASCO) have recommended that adjuvant therapy for stage II disease be considered and discussed with patients. Both panels strongly recommended that such treatment be given within clinical trials, when possible. In view of all these controversies more data is needed for patients with stage 2 colon cancer within and outside clinical trials setting.

Despite the limitation of small sample size, our study also showed a tendency toward better survival in the chemotherapy treated group, but the results remained statistically insignificant $(\mathrm{p}=0.056)$. In a separate univariate analysis done by Gill et al. (10), improvements with adjuvant chemotherapy did reach statistical significance for 5 -year DFS ( $72 \%$ vs. $76 \%$; $\mathrm{p}=0.0490$ ), but did 


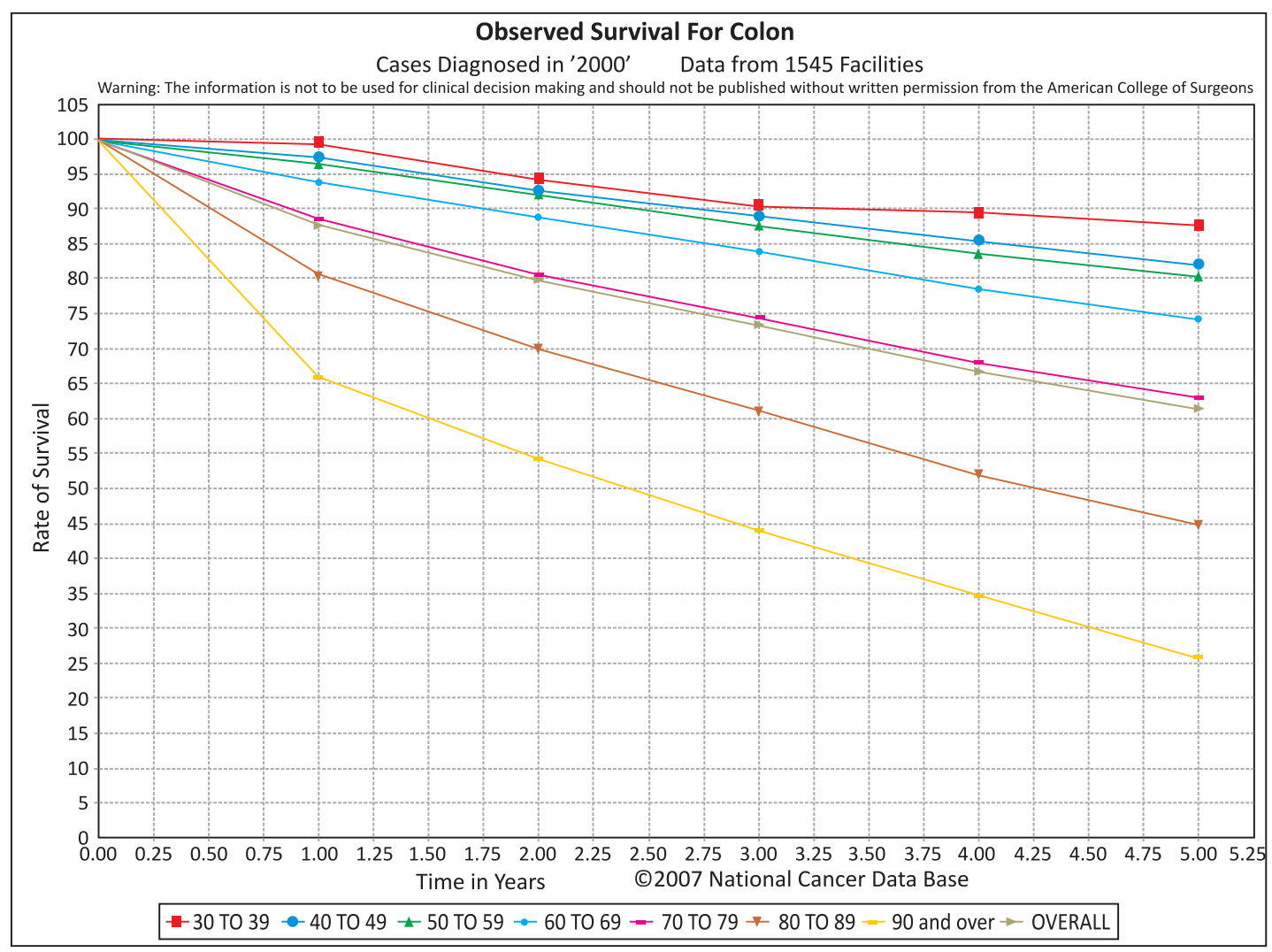

Figure 4 Observed survival in Stage II colon cancer patients diagnosed in 2000 from 1545 medical facilities from CoC Database and stratified by age (30-39, 40-49, 50-59, 60-69, 70-79, 80-89 and >90).

not for OS ( $80 \%$ vs. $81 \%$; $\mathrm{p}=0.1127)$. Therefore, adjuvant chemotherapy in Stage II colon cancer still remains a viable option, but an OS benefit is not readily evident for all subgroups of patients.

Our study is based on the retrospective analysis of the data and as such it has limited power to predict prospective outcomes. It is also limited by the small sample size (197 patients) and the non-availability of all the literature reported risk factors. It is another, albeit small, contribution to the data examining the still unresolved question of the role of the adjuvant chemotherapy in the treatment of stage II colon cancer.

Our findings that age of the patients represents the most important prognostic survival factor in this disease are consistent with data from CoC NCD. There was evident difference in survival between age groups (Figure 4) in this large national database. Patients 80-89 years of age had 5-year OS of $45 \%$, while patients older than 90 were alive after 5 years in only $25 \%$ of cases. Patients younger than 60 years old had 5-year OS between $80 \%$ and $92 \%$, with the very young group (30-39 years old) having excellent survival of $92 \%$. These survival numbers are comparable with the data provided in our study (33\% for patients older than 80 and $78 \%$ for patients younger than 63) confirming that patients treated in our hospital can expect survival similar to that achieved at national level. In our study data showed that patients were $5 \%$ more likely to die during the follow-up period for each year of age when entering study (with confidence interval between $3 \%$ and $7 \%$ ).

Our study did not confirm potential survival impact of any other risk factors 
analyzed. In accordance with historical experience, size of the tumor did not impact survival, supporting practice not to include this factor into colon cancer staging schema. Number of evaluated lymph nodes was previously shown to be important prognostic factor in colon cancer (17). Common explanation was that increased number of lymph nodes give us more reliable staging (Stage II vs. III). Herein we observed the same trend (border line statistical significance) in patients with single stage II colon cancer. Possible explanation for these findings is that elimination of larger number of lymph nodes reduces potentially residual burden of disease.

There is still controversy in the literature whether the number of lymph nodes resected and evaluated impacts patient outcomes (17-26). When lymph node (LN) number is used as categorical variable (> or $<$ than $12 \mathrm{LN}$ removed) was entered into the Cox model, results were consistent with those seen using LN count as a continuous variable $(\mathrm{HR}=0.98, \mathrm{CI}=0.62-1.56, \mathrm{p}=0.07)$. Therefore, our study does not support $12 \mathrm{LN}$ benchmark. We recommend re-evaluation of this specific benchmark.

In our study there was no association between the survival and the sex of the patient. The stage of the disease $2 \mathrm{~A}$ vs. $2 \mathrm{~B}$ did not reach statistical significance, but both the widespread confidence interval (0.76-2.35) and the hazard ratio of 1.34 probably indicates that the sample size for analysis was too small and may be the stage of the tumor in itself is not a reliable parameter for the survival analysis.

We did not have available advanced genetic test results such as Microsatellite instability or Colo print (27-32). These tests identify important markers of tumor biology and can serve as drivers of treatment decisions. This represents another limitation of this study. More data is still needed to identify markers capable of establishing which stage 2 patients will suffer from recurrence and which could potentially benefit from adjuvant treatment.

\section{Conclusion}

Our study despite its limitations of retrospective data collection and the small number of patients did show that adjuvant chemotherapy could potentially be beneficial for the survival of patients with Stage II colon cancer. In addition, the number of resected lymph nodes $(>12)$ seems to represent a distinct survival factor not only in Stage III, but also possibly in Stage II disease. However, the most important factor for survival is still age of the patient. Finally, survival of patients with Stage II colon cancer at Sparrow Hospital parallels national statistics for the United States of America.

Acknowledgements: We would like to extend our special thanks to Anna Delev from the user support services of the National Cancer Data base, American college of surgeons for granting permission to use the observed survival figure in our manuscript (Figure 4). We would like to thank Autumn Hozeska for data collection, Vasim Lala, Nandan Raval and Elaine Brantley all students from the Michigan State University College of Osteopathic Medicine student volunteers in manuscript preparation. We would like to thank Harini Gangur for her contribution towards the preparation of this manuscript.

Authors' contributions: All authors state that they have made contributions to this manuscript either through conception and design, data collections, analysis and interpretation of data, drafting the article, and critical revision for important intellectual content.

Conflict of interest: The authors declare that they have no conflict of interest.

\section{References}

1. Mamounas E, Wieand S, Wolmark N, Bear HD, Atkins JN, Song K, et al. Comparative efficacy of adjuvant chemotherapy in patients with Dukes' B versus Dukes' C colon cancer: Results from four National Surgical Adjuvant Breast and Bowel 
Project adjuvant studies (C-01, C-02, C-03, and C-04). J Clin Oncol. 1999;17(5):1349-55.

2. Efficacy of adjuvant fluorouracil and folinic acid in B2 colon cancer. International Multicentre Pooled Analysis of B2 Colon Cancer Trials (IMPACT B2) Investigators. J Clin Oncol. 1999;17(5):1356-63.

3. Marsoni S. international Multicenter Pooled Analysis of Colon Cancer Trials Investigators. Efficacy of adjuvant fluorouracil and leucovorin in stage B2 and C colon cancer. International Multicenter Pooled Analysis of Colon Cancer Trials Investigators. Semin Oncol. 2001 Feb;28(1 Suppl 1):14-9.

4. NIH Consensus Conference. Adjuvant therapy for patients with colon and rectal cancer. JAMA. 1990;264(11):1444-50.

5. Moertel CG, Fleming TR, Macdonald JS, Haller DG, Laurie JA, Goodman PJ, et al. Levamisole and fluorouracil for adjuvant therapy of resected colon carcinoma. N Engl J Med. 1990;322(6):352-8.

6. Andre T, Boni C, Mounedji-Boudiaf L, Navarro M, Tabernero J, Hickish T, et al. Oxaliplatin, fluorouracil, and leucovorin as adjuvant treatment for colon cancer. N Engl J Med. 2004;350(23)2343-51.

7. De Gramont A, Boni C, Navarro M, Tabernero J, Hickish T, Topham C, et al. Oxaliplatin/5-FU/LV in stage II and III colon cancer: Updated results (as of January 04) for efficacy and neurotoxicity of the MOSAIC trial [abstract]. Ann Oncol. 2004;15 Suppl 3:275PD.

8. Food and Drug Administration. Eloxatin: New or modified indication. Washington, DC: US Food and Drug Administration; 2004.

9. Figueredo A, Charette ML, Maroun J, Brouwers MC, Zuraw L. Adjuvant therapy for stage II colon cancer: A systematic review from the Cancer Care Ontario Program in evidence-based care's gastrointestinal cancer disease site group. J Clin Oncol. 2004;22(16):3395-407.

10. Gill S, Loprinzi CL, Sargent DJ, Thome SD, Alberts SR, Haller DG, et al. Pooled analysis of fluorouracil-based adjuvant therapy for stage II and III colon cancer: Who benefits and by how much? J Clin Oncol. 2004;22(10):1797-806.

11. Gray RG, Barnwell J, McConkey C, Hills RK, Williams NS, Kerr D, et al. QUASAR: A randomized study of adjuvant chemotherapy (CT) vs observation including 3238 colorectal cancer patients [abstract]. J Clin Oncol. 2004;22 (Suppl):14S.

12. Jemal A, Murray T, Ward E, Samuels A, Tiwari RC, Ghafoor A,et al. Cancer Statistics, 2005. CA Cancer J Clin. 2005;55(1):10-30.

13. Schrage D, Rifas-Shiman S, Saltz L, Bach PB, Begg CB. Adjuvant chemotherapy use for Medicare beneficiaries with stage II colon cancer. J Clin Oncol. 2002;20(19):3999-4005.

14. Gryfe R, Kim H, Hsieh ET, Aronson MD, Holowaty EJ, Bull SB, et al. Tumor microsatellite instability and clinical outcome in young patients with colorectal cancer. N Engl J Med. 2000;342(2):69-77.

15. American College of Surgeons [www.facs.org]. Chicago: American College of Surgeons; c19962012 [updated 2012 Jul 3; cited 20 Jul 2012]. Available from http://www.facs.org/cancer.

16. O’Connell JB, Maggard MA, Ko CY. Colon cancer survival rates with the new American Joint Committee on Cancer sixth edition staging. J Natl Cancer Inst. 2004;96(19):1420-5.

17. Sarli L, Bader G, Iusco D, Salvemini C, MauroDD, Mazzeo A, et al. Number of lymph nodes examined and prognosis of TNM stage II colorectal cancer. Eur J Cancer. 2005;41(2):272-9.

18. Nelson H, Petrelli N, Carlin A, Couture J, Fleshman J, Guillem J, et al. Ota D, Sargent D: Guidelines 2000 for colon and rectal cancer surgery. J Natl Cancer Inst. 2001;93:583-96.

19. Edge SB, Byrd DR, Compton CC, Fritz AG, Greene FL, Trotti A. American Joint Committee on Cancer, American Cancer Society: AJCC Cancer Staging Manual. 7th edition. New York, NY: Springer-Verlag; 2010.

20. Romanus D, Weiser MR, Skibber JM, Ter Veer A, Niland JC, Wilson JL, et. al. Concordance with NCCN Coloreactal Cancer Guidelines and ASCO/ NCCN quality measures: An NCCN institutional Analysis. J Natl Compr Canc Netw. 2009;7:895904.

21. Chang GJ, Kaiser AM, Mills S, Rafferty JF, Buie WD. Standards Practice Task Force of the American Society of Colon and Rectal Surgeons. Dis Colon Rectum. 2012;55(8):831-43.

22. Corrigan JM. National Quality Forum (NQF), National Voluntary Consensus Standards for quality of cancer care. Washington DC: National Quality Forum; 2009.

23. Sandra L. Wong Lymph node counts and survival rates after resection for Colon and Rectal cancer. Gastrointest Cancer Res. 2009;3(2 Suppl 1):S33-5.

24. Wong SL, Ji H, Hollenbeck BK, Morris AM, Baser O, Birkmeyer JD. Hospital lymph node examination rates and survival after resection for colon cancer. JAMA. 2007;298(18):2149-54.

25. Baxter NN, Virnig DJ, Rothenberger DA, Morris AM, Jessurun J, Virnig BA. Lymph node evaluation in colorectal cancer patients: a populationbased study. J Natl Cancer Inst. 2005;97(3):219-25.

26. Watanabe T, Kobunai T, Yamamoto Y, Matsuda K, Ishihara S, Nozawa K, et al. Chromosomal insta- 
bility (CIN) phenotype, CIN high or CIN low, predicts survival for colorectal cancer. J Clin Oncol. 2012;30(18):2256-64.

27. Van Engeland M, Derks S, Smits K, Meijer GA, Herman JG. Colorectal cancer epigenetics: complex simplicity. J Clin Oncol. 2011;29(10):138291.

28. Salazar R, Roepman P, Capella G, Moreno V, Simon I, Dreezen C, et al. Gene expression signature to improve prognosis projection of stage II and III colorectal cancer. J Clin Oncol. 2011;29(1):17-24.

29. Gray RG, Quirke P, Handley K, Lopatin M, Magill L, Baehner FL, et al. Validation study of a quantitative multigene reverse transcriptase-polymerase chain reaction assay for assessment of recurrence risk in patients with stage II colon cancer. J Clin Oncol. 2011;29(35):4611-9.
30. Kennedy RD, Bylesjo M, Kerr P, Davison T, Black JM, Kay EW, et al. Development and independent validation of a prognostic assay for stage II colon cancer using formalin-fixed paraffin-embedded tissue. J Clin Oncol. 2011;29(35):4620-6.

31. Zhang J, Song W, Chen Z, Wei J, Lio, Y, Hu M, et al. Prognostic and predictive value of a microRNA signature in stage II colon cancer: a microRNA expression analysis. Lancet Oncol. 2013;14:1295306.

32. Young JL Jr, Roffers SD, Ries LAG, Fritz AG, Hurlbut AA, editors. SEER Summary Staging Manual - 2000: Codes and Coding Instructions, National Cancer Institute, NIH Pub. No. 01-4969. Bethesda, MD: National Cancer Institute; 2001. 